Article

\title{
The Influence of the Wind Measurement Campaign Duration on a Measure-Correlate-Predict (MCP)-Based Wind Resource Assessment
}

\author{
José V. P. Miguel ${ }^{1, *(\mathbb{D}}$, Eliane A. Fadigas ${ }^{2}$ and Ildo L. Sauer ${ }^{1}$ \\ 1 Institute of Energy and Environment, University of São Paulo, Avenida Professor Luciano Gualberto, 1289, \\ São Paulo CEP 05508-010, Brazil; illsauer@iee.usp.br \\ 2 Department of Electrical Engineering, University of São Paulo, Avenida Professor Luciano Gualberto, \\ Travessa 3, n. 158, São Paulo CEP 05508-970, Brazil; elianefadigas@usp.br \\ * Correspondence: jose.miguel@usp.br; Tel.: +55-11-3091-2500
}

Received: 15 August 2019; Accepted: 15 September 2019; Published: 20 September 2019

\begin{abstract}
Driven by the energy auctions system, wind power in Brazil is undergoing a phase of expansion within its electric energy mix. Due to wind's stochastic nature and variability, the wind measurement campaign duration of a wind farm project is required to last for a minimum of 36 months in order for it to partake in energy auctions. In this respect, the influence of such duration on a measure-correlate-predict (MCP) based wind resource assessment was studied to assess the accuracy of generation forecasts. For this purpose, three databases containing time series of wind speed belonging to a site were considered. Campaigns with durations varying from 2 to 6 years were simulated to evaluate the behavior of the uncertainty in the long-term wind resource and to analyze how it impacts a wind farm power output estimation. As the wind measurement campaign length is increased, the uncertainty in the long-term wind resource diminished, thereby reducing the overall uncertainty that pervades the wind power harnessing. Larger monitoring campaigns implied larger quantities of data, thus enabling a better assessment of wind speed variability within that target location. Consequently, the energy production estimation decreased, allowing an improvement in the accuracy of the energy generation prediction by not overestimating it, which could benefit the reliability of the Brazilian electric system.
\end{abstract}

Keywords: wind measurement campaign; wind resource assessment; MCP methods; long-term wind resource uncertainty

\section{Introduction}

As of 2009, the expansion of wind power in the Brazilian electrical energy mix [1,2] was bolstered by a bidding mechanism that promoted competitiveness among different energy sources. This auction-based systematic concept favored the reduction of electricity prices, making wind power generation competitive with other well-explored power sources within the Brazilian electric power sector, such as hydro and thermal [3,4]. Furthermore, it was shown that it would be preferable, at competitive prices, to meet the Brazilian new demand for energy with only renewable sources such as wind instead of thermal power [5].

Due to the stochastic nature of wind resources (i.e., a characteristic that determines variability in its availability), predicting wind power generation is an uncertain process and, thereby, acquiring knowledge of the historical behavior of wind is essential to estimate how much electricity a wind farm can produce and deliver to the grid [6-8]. Wind resources vary in different temporal scales, from the shortest (seconds), to intermediate (hours to days), to longer timescales (months to years to decades) [9]. It can be worrisome if interannual variability is neglected when designing a wind 
farm, to the extent that it could lead to overconfidence in the wind resources $[10,11]$. Several authors address the interannual variability as an issue to be dealt with if a better balance between electricity production and demand is sought [10-15]. Countries like Brazil, which lack the access to wind data recorded over a broad area and over long, multi-decadal periods, face the task of estimating its wind power potential where only short-term datasets resulting from recent wind measurement campaigns are available, since these are not able to represent the wind interannual variability. For that challenge to be overcome, the use of reanalysis data and measure-correlate-predict (MCP) methods is necessary.

$\mathrm{MCP}$ is a technique that is able to hindcast wind resources in a given target location where periodical measurements of wind speed and direction are carried out over a short period of time (usually from 12 to 36 months) [7]. The methodology is an important step of the wind resource assessment (WRA), which can historically characterize the local wind behavior. However, wind data that is representative for longer timescales is required for the MCP and WRA to provide accurate knowledge about the local long-term wind variability and also to estimate the power output of a wind farm throughout its multidecadal lifespan $[7,16]$. Even though presenting significant uncertainties, reanalysis databases are commonly used to fill the gap in locations lacking long-term reference datasets because they result from a combination of different meteorological observations and numerical weather prediction models, providing coverage for large areas and long periods $[17,18]$. The $\mathrm{MCP}$, as much as other WRA steps and reanalysis databases themselves, is subject to an uncertainty degree inherent to the unpredictability of the wind behavior. Thereby, the identification and quantification of this group of uncertainties is relevant when it comes to reliably determining the local wind energy potential [19], which in turn directly affects the financial structure of wind power projects [20,21].

In Brazil, there is a minimum duration regarding the wind measurement campaign for a project to be able to participate in energy auctions. This minimum length for short-term datasets was extended from 24 to 36 whole months from 2017 onwards [22]. The duration of the campaign is a relevant matter, since it indirectly dictates the volume of data to be used in the MCP, determining the concurrent period of data between target and reference locations. Longer periods of measurement tend to better outline the local wind variability $[16,23]$. Therefore, this recent Brazilian measure could improve the understanding of wind resources natural variability and, consequently, lead to a probable reduction regarding the group of uncertainties that pervades the WRA. Moreover, it is expected that new wind farm projects could more accurately reflect the reality of wind power generation in Brazil.

Few authors have studied the length of the concurrent data between short and long-term datasets. In [16], Rogers et al. stated that the longer the short-term dataset, the smaller the standard deviation of MCP predictions of mean wind speed becomes. Also, in [23], Taylor et al. affirmed that by increasing the duration of data collection it is possible to reduce the uncertainty in wind speed. Yet no research proposed to evaluate if longer short-term datasets could improve the WRA by influencing its overall uncertainty and, ultimately, the wind power output estimation. Given the aforementioned, the contribution of this article regards the assessment of how the uncertainty related to the long-term historical characterization of wind resources in a target location is affected by the increase in the wind measurement campaign timespan. Subsequently, the research aims to analyze if this longer monitoring period could promote enhancements in the estimation of power generation in a hypothetical scenario of a wind farm set in that target location.

\section{Materials and Methods}

\subsection{Wind Data}

Fundamental for the study of wind resources, anemometric data containing periodical records of wind speed were obtained for this research: In total, three databases consisting of numerical time series with information on the wind speed measured at different heights above ground level, also including information about air density. Table 1 sums up the characterization of the data according to certain parameters, including the altitude of both the target and reference locations, the measurement height 
(above ground level), the dates when the first and last measurements were taken, the periodicity with which the data were recorded, and average wind speed for the whole measurement campaign.

Table 1. Characterization of the databases of interest.

\begin{tabular}{cccccccc}
\hline Data Base & Location & $\begin{array}{c}\text { Altitude } \\
{[\mathrm{m}]}\end{array}$ & $\begin{array}{c}\text { Measurement } \\
\text { Height }[\mathbf{m}]\end{array}$ & $\begin{array}{c}\text { Initial } \\
\text { Measurement } \\
\text { Date }\end{array}$ & $\begin{array}{c}\text { Final } \\
\text { Measurement } \\
\text { Date }\end{array}$ & $\begin{array}{c}\text { Periodicity } \\
{[\text { Minutes] }}\end{array}$ & $\begin{array}{c}\text { Average Wind } \\
\text { Speed [m/s] }\end{array}$ \\
\hline 1 & Target & 877 & 42 & 1 January 2009 & 31 December 2014 & 10 & 8.204 \\
1 & Target & 877 & 66 & 1 January 2009 & 31 December 2014 & 10 & 8.759 \\
1 & Target & 877 & 81 & 1 January 2009 & 31 December 2014 & 10 & 9.174 \\
2 & Target & 1053 & 42 & 1 January 2009 & 31 December 2014 & 10 & 10.063 \\
2 & Target & 1053 & 66 & 1 January 2009 & 31 December 2014 & 10 & 10.164 \\
2 & Target & 1053 & 81 & 1 January 2009 & 31 December 2014 & 10 & 10.257 \\
3 & Reference & 829 & 50 & 1 January 2009 & 31 December 2014 & 60 & 5.906 \\
\hline
\end{tabular}

Other target and reference locations were considered for this research but, due to poor correlation, they did not meet the criteria to perform a MCP-based WRA, as seen in Appendix A.

Databases 1 and 2 (D1 and D2) both represent the target location and are $18 \mathrm{~km}$ away from one another. Their measurements carried out by anemometers installed in two meteorological masts; each of these towers has three wind speed sensors at three different heights $(42,66$ and $81 \mathrm{~m}$ above ground level) and they record short-term periods of six complete years of records at every $10 \mathrm{~min}$. Database 3 (D3) represents the reference location and is situated $20 \mathrm{~km}$ away from D1 and $38 \mathrm{~km}$ away from D2. It comprehends a long-term measurement period of 30 years with records of wind speed at a height of $50 \mathrm{~m}$ (above ground level) every $60 \mathrm{~min}$. The data belonging to D3 was obtained from a reanalysis study denominated Modern Era Retrospective-analysis for Research and Applications (MERRA) [24]. The information held within this time series results from tridimensional climate data in a global scale, combining past observations from different measurement systems numerically modeled to predict and to construct the evolution of the Earth's climate throughout time $[17,18,25]$. The choice of using MERRA as a wind reference data provider is justified by two reasons: Proximity with D1 and D2, and the fact that it allows satisfying results concerning the representativeness of the long-term wind regime for a target location [26,27].

Each of these databases illustrates the wind behavior of a specific geographic location. However, they are located in the same micro region of Bahia (one of the Brazilian Northeastern states), where the terrain complexity (Figure 1) implies wind flow changes, such as accelerations, decelerations and wind direction deviations, making the targeted wind regime unique. The fact that all three datasets are close to each other favors the possibility of a good correlation between data from both target and reference locations [28]. 


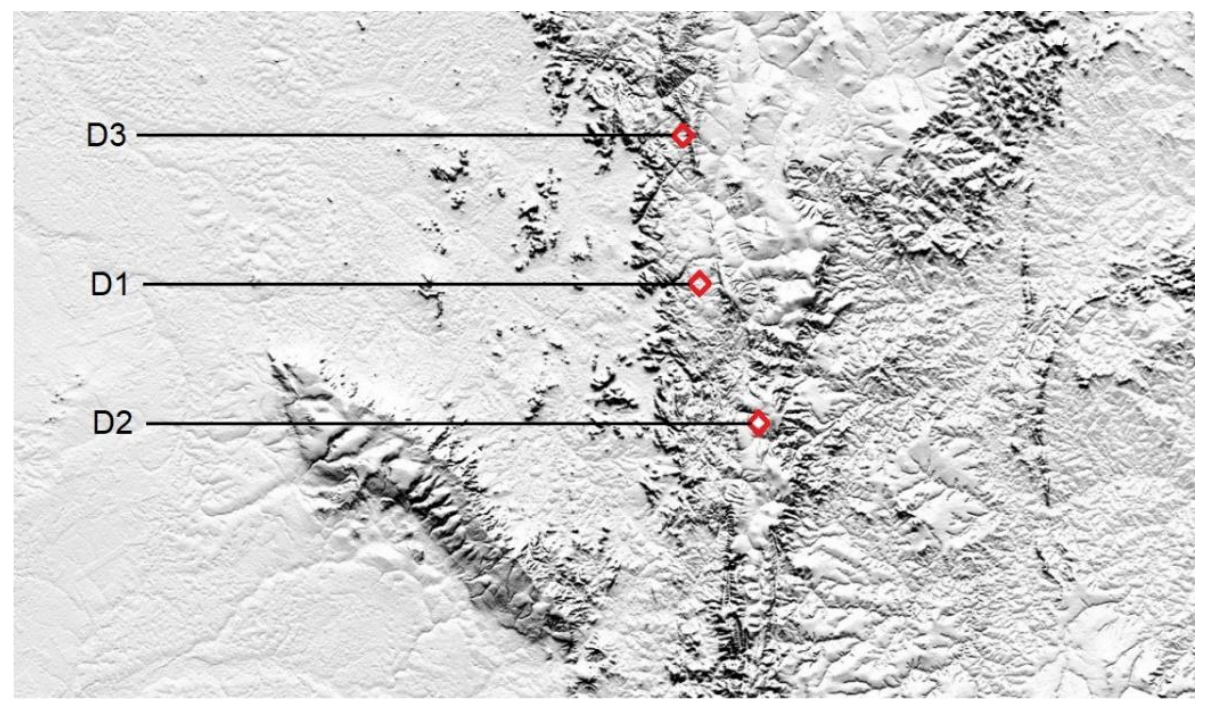

Figure 1. Orographic details of the databases' specific locations, D1, D2 and D3.

\subsection{MCP Methods}

The measure-correlate-predict (MCP) technique is applied to promote the historical characterization of wind resources. The MCP is an important tool to retrospectively reproduce long-term wind conditions of the target location where only short-term data is available. For that to be performed, a correlation between concurrent short-term data for two different locations is initially established; one of them being the target location, where wind resources are to be exploited, and the other being the reference location, where consistent long-term data is available. Secondly, the resulting correlation is employed over the full long-term reference time series to synthesize a long-term time series for the target location. The simultaneity whereby the short-term data from both the target and the reference location were recorded is vital for applying the MCP methods [25].

Various MCP methods have been proposed in the scientific literature, most of which were reviewed in [25]. Some of them are based on linear [16,29-35] and non-linear [36-38] regression techniques; others are based on a probabilistic distribution of wind data for the target location [39-45], but all of these consider one single reference station. Nevertheless, some methods take into account multiple reference stations [46-50]. Among such different MCP methods, designing a wind farm would require the proper selection of a method that better suits the datasets for the target and reference stations, since different methods differ from each other on the relationship they establish between the datasets representing the target and reference locations [25]. Hence, comparing distinct methods is necessary before electing a single one to proceed with the WRA. Several studies worked on this matter of comparing different MCP methods according to metrics such as mean absolute error, mean absolute relative error or mean squared error [51-61]. Nonetheless, there is no consensus about one single best MCP model, reinforcing the necessity of testing several of them for every set of wind data.

For performing the MCP-based historical characterization of the wind regime represented by D1, D2 and D3, this research resorted to a software widely used by the wind power industry: Windographer. This software can run tests with the datasets and automatically compare the errors (mean absolute error (MAE), and root mean squared error (RMSE)) of some methods such as Linear Least Squares [16], Matrix Time Series [44], SpeedSort [33], Total Least Squares [32], Variance Ratio [16], Vertical Slice [34,36] and Weibull Fit [38]. Due to relative smaller errors, the Vertical Slice method was elected to proceed with the MCP calculation and to synthesize long-term time series of wind data. In this method, the dispersion diagram of pairs (wind speed at target location versus concurrent wind speed at reference location) is sectioned into equally sized vertical stripes. Later, the algorithm calculates the mean values of the target location wind speed for each stripe, marking down on the diagram a pair 
between the latter values and the mean values of each stripe. The linear fit is then conducted by the linear connection of the pairs, originating the first line in $(0,0)[25,34,36]$.

The MCP should be executed with data recorded at similar measurement heights for both the target and reference locations, so that the synthesized data can later be adjusted to the wind turbine hub height $[25,62]$. Thus, the Vertical Slice method was implemented to extend different time series with measurements at $42 \mathrm{~m}$ in hindsight (for both D1 and D2), using wind data from D3 as the reference location data, which are given at $50 \mathrm{~m}$ above ground level. The original data of D1 and D2 (six years of wind speed measurements for each) was cut into different sub datasets, providing extracted short-term time series of different time lengths that simulate wind monitoring campaigns varying in their durations. In total, five short-term time series for each target location dataset, D1 and D2, were analyzed, and they differ in their time spans (or $N_{\mathrm{T}}$, the number of integer years of measurement): 2 whole years (from 2013 to 2014), 3 whole years (from 2012 to 2014), 4 whole years (from 2011 to 2014), 5 whole years (from 2010 to 2014), and 6 whole years (from 2009 to 2014).

The 10 resulting MCP-synthesized long-term time series contain wind speed data that correspond to measurements at $42 \mathrm{~m}$ in height, preserving the original measurement height from D1 and D2. All the data had to be vertically extrapolated (using Equations (1) and (2) [6-8]) to the turbine hub height, which was considered $81 \mathrm{~m}$ above ground level. In Equations (1) and (2), $V(h)$ is the average wind speed for a given height $h, \beta$ is a constant intrinsic to the local vertical wind profile and $\alpha$ is the power law exponent, also intrinsic to the local vertical wind profile. The characterization of the wind speed vertical profile at the target location (represented by D1 and D2) is presented in Table 2. The schematic view of the process described in Section 2.2 is seen in Figure 2.

Table 2. Characterization of the wind speed vertical profile of D1 and D2.

\begin{tabular}{ccccc}
\hline \multirow{2}{*}{$\begin{array}{c}\text { Above Ground } \\
\text { Height }[\mathrm{m}]\end{array}$} & \multicolumn{2}{c}{ Data from D1 } & \multicolumn{2}{c}{ Data from D2 } \\
\cline { 2 - 5 } & $\begin{array}{c}\text { Average Wind } \\
\text { Speed [m/s] }\end{array}$ & $\begin{array}{c}\alpha \text { Exponent } \\
\text { (Power Law) }\end{array}$ & $\begin{array}{c}\text { Average Wind } \\
\text { Speed [m/s] }\end{array}$ & $\begin{array}{c}\alpha \text { Exponent } \\
\text { (Power Law) }\end{array}$ \\
\hline 81 & 9.175 & & 10.741 & \\
66 & 8.800 & 0.1680 & 10.642 & 0.0879 \\
42 & 8.204 & & 10.158 & \\
\hline
\end{tabular}




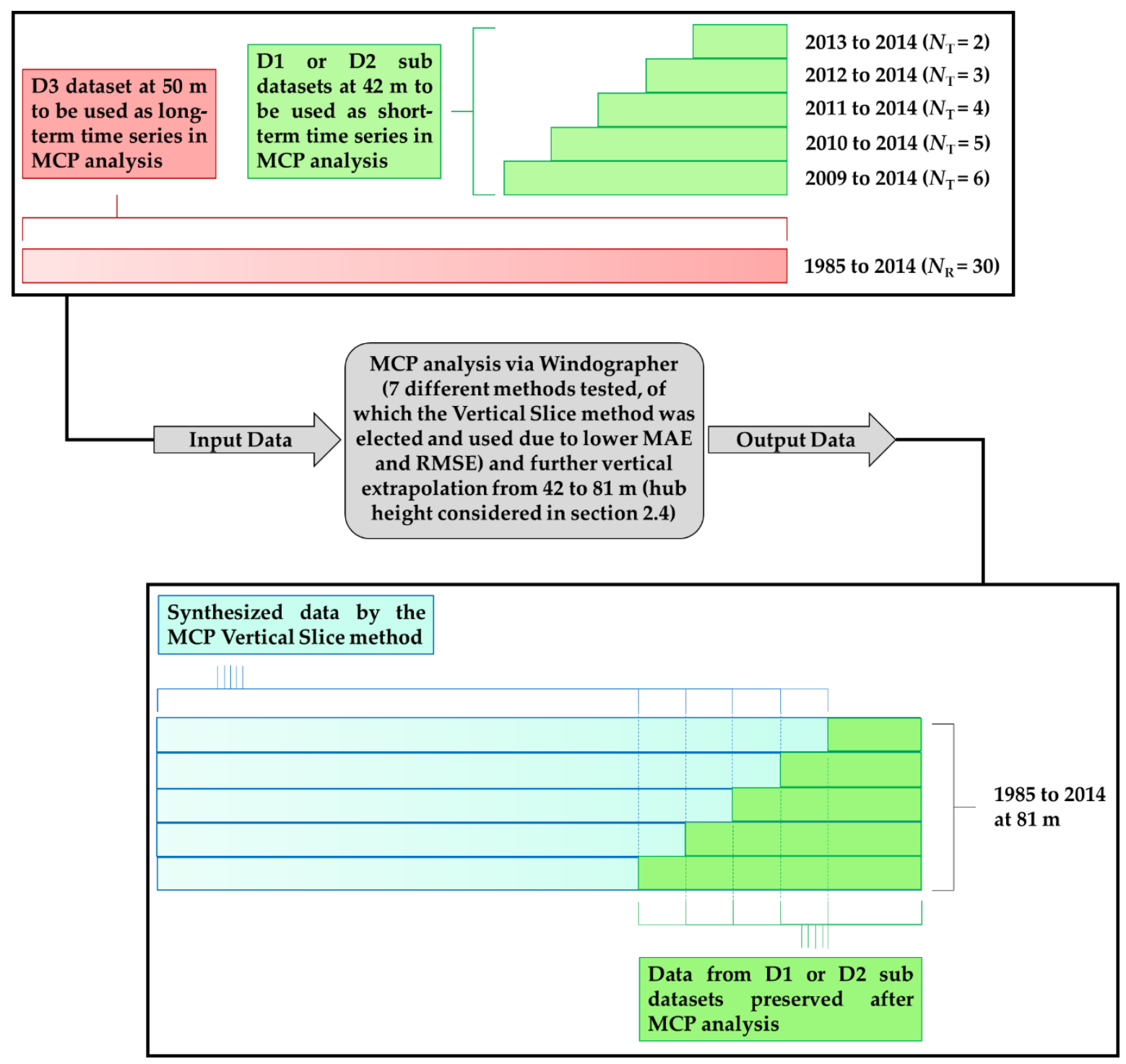

Figure 2. Measure-correlate-predict (MCP) analysis with the Vertical Slice method-elected due to lower mean absolute error (MAE) and root mean squared error (RMSE) and further vertical extrapolation of data.

$$
\begin{gathered}
V(h)=\beta \cdot h^{\alpha} \\
\ln (V(h))=\alpha \cdot \ln (h)+\ln (\beta)
\end{gathered}
$$

\subsection{Long-Term Wind Resource Uncertainty}

The uncertainty associated with the long-term historical characterization of wind resources in the target location (represented by $\sigma_{\mathrm{H}}$, or historical uncertainty) concerns the year-on-year variability of the wind speed [19]. Equation (3) is suggested in [7] to calculate $\sigma_{\mathrm{H}}$, where $\sigma_{\mathrm{R}}$ represents the standard deviation regarding the yearly averaged wind speeds of the reference location. $r^{2}$ is the squared Pearson correlation between the concurrent wind speed data from both the target and reference locations, provided that the data is averaged with equivalent periodicity; $N_{R}$ and $N_{T}$ respectively quantify the integer number of years of measurement of the reference database (D3) and the integer number of years of concurrent data between the target databases (D1 or D2) and D3. 


$$
\sigma_{\mathrm{H}}=\sqrt{\left(\frac{r^{2}}{N_{\mathrm{R}}}\right) \sigma_{\mathrm{R}}^{2}+\left(\frac{\left(1-r^{2}\right)}{N_{\mathrm{T}}}\right) \sigma_{\mathrm{T}}^{2}}
$$

Given that D3 collects wind speed data from 1985 to $2014, N_{\mathrm{R}}$ is fixed at 30 . The variable $N_{\mathrm{T}}$, however, varies from 2 to 6, since D1 and D2 uses wind data ranging from 2009 to 2014. $N_{\mathrm{T}}$ indirectly represents the length of the wind monitoring campaign; therefore, for each set of two time series related and considered for calculating $\sigma_{\mathrm{H}}$, five different periods were explored, as cited before. $r^{2}$ was also affected by the duration of the wind monitoring campaign due to being related to the quantity of data contained in the target location time series, as shown in Table 3.

Table 3. Squared Pearson correlation $\left(r^{2}\right)$ between data from D1 or D2 at different heights and different wind monitoring campaign lengths in combination with data from D3.

\begin{tabular}{cccccccc}
\hline$N_{\mathrm{T}}$ (Period) & $\begin{array}{c}\text { D1-81 m and } \\
\text { D3-50 m }\end{array}$ & $\begin{array}{c}\text { D1-66 } \mathbf{m} \text { and } \\
\text { D3-50 m }\end{array}$ & $\begin{array}{c}\text { D1-42 } \mathbf{~ m} \text { and } \\
\text { D3-50 m }\end{array}$ & $\begin{array}{c}\text { D2-81 m and } \\
\text { D3-50 m }\end{array}$ & $\begin{array}{c}\text { D2-66 m and } \\
\text { D3-50 m }\end{array}$ & $\begin{array}{c}\text { D2-42 m and } \\
\text { D3-50 m }\end{array}$ \\
\hline $2(2013-2014)$ & 0.425 & 0.430 & 0.449 & 0.461 & 0.464 & 0.481 \\
\hline $3(2012-2014)$ & 0.434 & 0.438 & 0.457 & 0.475 & 0.476 & 0.493 \\
\hline $4(2011-2014)$ & 0.446 & 0.451 & 0.468 & 0.487 & 0.488 & 0.505 \\
\hline $5(2010-2014)$ & 0.443 & 0.446 & 0.462 & 0.486 & 0.484 & 0.503 \\
\hline $6(2009-2014)$ & 0.447 & 0.451 & 0.467 & 0.489 & 0.488 & 0.510 \\
\hline
\end{tabular}

The original data from D1 and D2 was hourly averaged so that they could match D3's periodicity of $60 \mathrm{~min}$. Later on, the historical uncertainty was calculated according to the length of each time series (regarding the target location) and its respective measurement height. For each of the three measurement heights of D1 and D2 and for each of the five periods of measurement, one value of $\sigma_{\mathrm{H}}$ resulted, accumulating a total of 30 values, as seen in Figure 3.

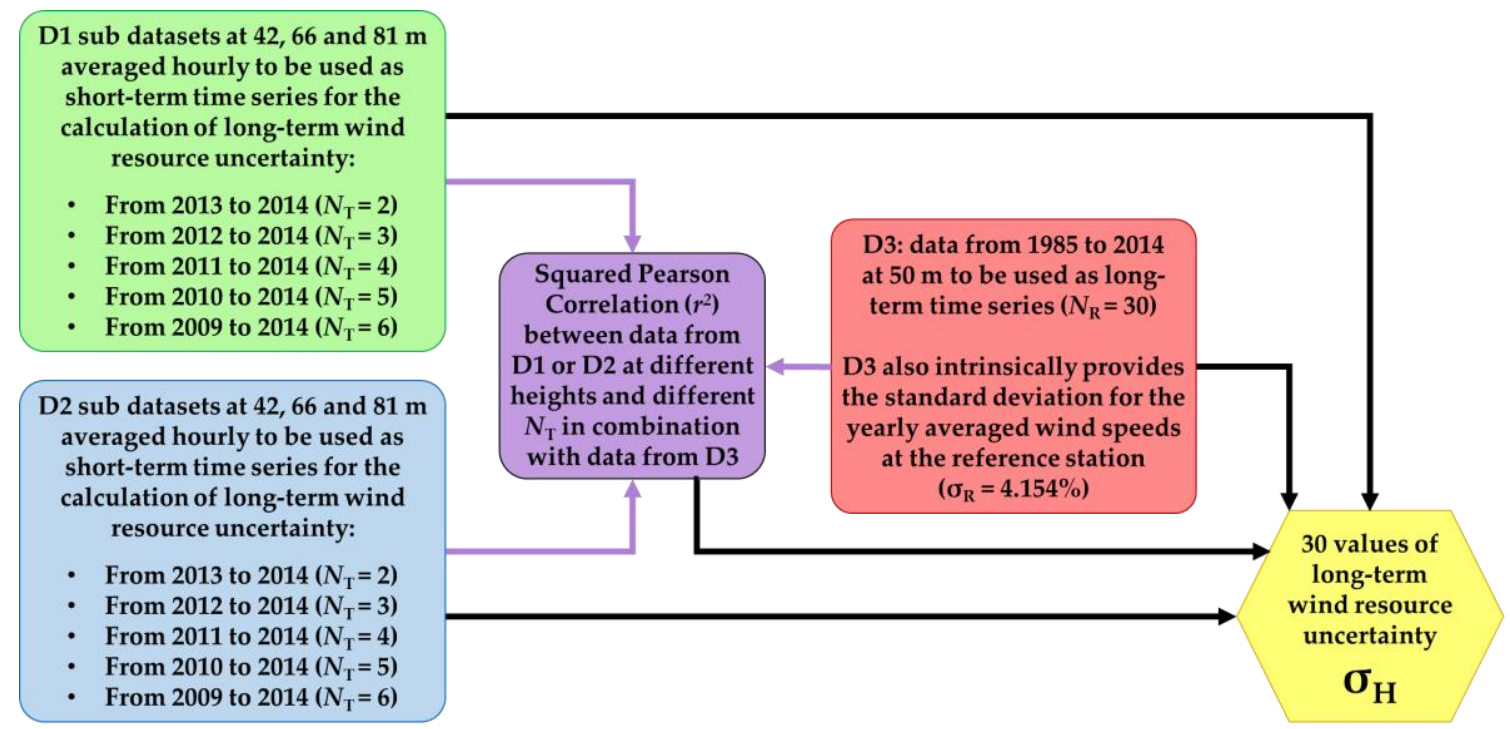

Figure 3. Schematic view of the target location long-term wind resource uncertainty characterization.

\subsection{Wind Power Output Estimation}

The estimation of wind farm power production is linked to the uncertainties identified and quantified during the execution of the WRA. In Brazil, the regulation requires that projects willing to participate in an energy auction must adopt a probability of occurrence of $90 \%\left(P_{90}\right)$ regarding the total energy production estimated to those projects' wind farms throughout their lifespans [22]. Equation (4) indicates how those calculations are made, where $E$ represents the maximum energy the wind farm can 
deliver to the grid; $L_{\mathrm{B}}$ and $L_{\mathrm{W}}$ are the losses due to blades degradation and wake effect, respectively; $E_{\mathrm{t}}$ is the energy output for a wind turbine; $P_{90}$ is a constant related to the normal distribution for that probability of occurrence of $90 \%$ and is equal to 1.28155; $O U$ is the overall uncertainty; $F U$ is the forced unavailability of the wind farm; $P U$ is the programmed unavailability of the wind farm; and $C L$ is the estimated internal consumption and electrical losses from the wind farm to its connection with the grid [22].

The $O U$ is calculated by Equation (5), where $u$ is an uncertainty of type $k$ and $U$ is the total number of identified uncertainties during the WRA [19]. All the parameters used for calculating $O U$ are displayed in Table 4 and their values were adopted arbitrarily based on a typical range $[63,64]$. $E_{\mathrm{t}}$ is obtained via Equation (6), which takes into account the characteristics of the wind turbine $\left(C_{p}\right.$ is the coefficient of power and $A$ is the circular area swept by the turbine blades), $\rho$ the instantaneous air density (given in D1 and D2), the wind speed at the turbine height ( $V$, given by the resulting MCP-synthesized time series extrapolated to $81 \mathrm{~m}$ ), and the number of hours in a given year (8760) [65].

Table 4. Losses and uncertainties.

\begin{tabular}{ccc}
\hline Losses (Calculation of $E$ ) & Considered Value [\%] & Typical Range [\%] \\
\hline Wake effect & 5.0 & - \\
Blades degradation & 0.5 & - \\
Forced unavailability $(F U)$ & 2.0 & $0.0-5.0$ \\
Programmed unavailability $(P U)$ & 4.0 & $2.0-10.0$ \\
Internal consumption and electrical losses & 3.0 & $2.0-3.0$ \\
$(C L)$ & & Typical Range [\%] \\
\hline Uncertainty Types (Calculation of $\mathrm{OU})$ & Considered Value [\%] & $0.2-3.0$ \\
\hline Installation of equipment & 2.0 & $0.5-4.0$ \\
Anemometer class & 1.0 & $0.5-3.0$ \\
Anemometers calibration & 2.0 & $0.0-2.0$ \\
Availability and acquisition of data & 1.0 & $0.5-5.0$ \\
Historical characterization of wind resources & $\sigma_{\mathrm{H}}$ & $1.0-10.0$ \\
Vertical extrapolation of wind data & 5.0 & $1.0-10.0$ \\
Terrain modelling & 5.0 & $5.0-10.0$ \\
Wind turbine power curve & 7.0 &
\end{tabular}

$$
\begin{gathered}
E=E_{\mathrm{t}} \cdot\left[\left(1-\left(1-\left(1-L_{\mathrm{B}}\right)\left(1-L_{\mathrm{W}}\right)\right)\right) \cdot\left(1-\left(P_{90} \cdot O U\right)\right) \cdot(1-F U) \cdot(1-P U)-C L\right] \\
O U=\sqrt{\sum_{k=1}^{U} u_{k}^{2}} \\
E_{\mathrm{t}}=\frac{1}{2} C_{p} \cdot \rho \cdot A \cdot V^{3} \cdot 8760
\end{gathered}
$$

Each of these uncertainty types $(k)$ presented in Table 4 has its own degree of importance and a typical range that varies according to the specifications of the target location. Altogether, they constitute the overall uncertainty, which directly influences the power output estimation of a wind farm. However, the selected subject for scrutiny was the uncertainty related to the historical characterization of wind resources and one of the goals for this work is to assess the sensitivity of the wind power output estimation to different values of this uncertainty factor, which, in turn, are sensitive to the wind monitoring campaign timespan.

The process of energy output estimation considering all the addressed variables to this research is illustrated on Figure 4. For instance, another factor of influence such as turbulence was disregarded in this research's analysis. Although the location of D1, D2 and D3 seems to be a terrain of relevant roughness (Figure 1) which could provoke enough turbulence to disturb wind turbine dynamics $[66,67]$, it is noteworthy that this is not a general model of factors of influence for the wind farm power output 
estimation. This research addresses one single uncertainty factor (yellow box on Figure 4) among several (orange box on Figure 4), associated with the increase in the wind monitoring campaign duration.

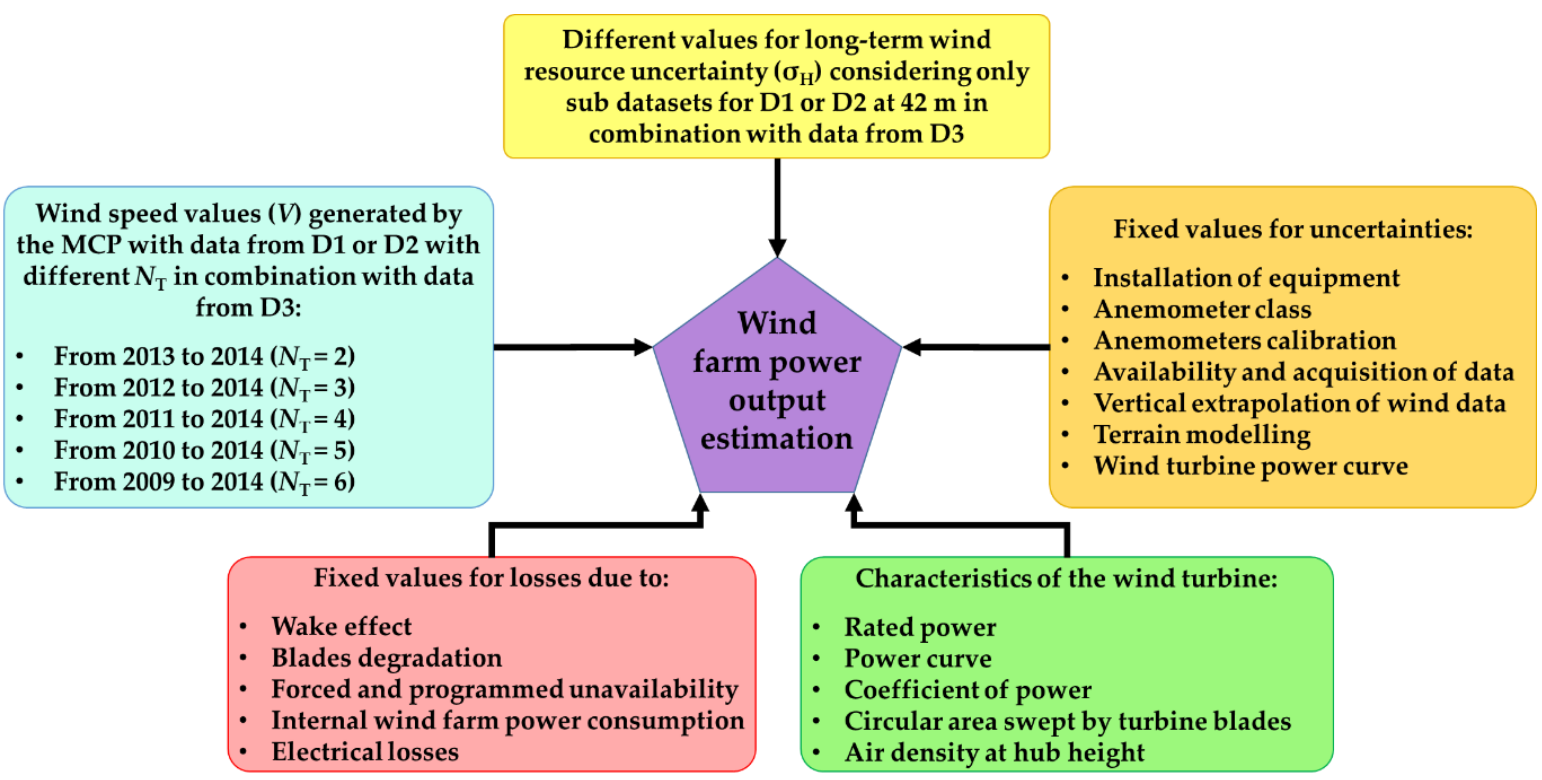

Figure 4. Wind farm power output estimation and all its influence factors.

\section{Results and Discussion}

In each of the six combinations between time series belonging to the target location (and its following measurement heights) and time series from the reference location, the tendency to reduce the historical uncertainty regarding the increase in the length of the wind monitoring campaign was evident. In relation to the 2 year duration, all the cases showed an average reduction of $18 \%, 29 \%, 35 \%$, and $40 \%$ when, respectively, one, two, three, and four years were added to the monitoring campaign, as observed in Table 5.

Table 5. Historical uncertainty $\left(\sigma_{\mathrm{H}}\right)$ considering different wind monitoring campaign lengths [\%].

\begin{tabular}{|c|c|c|c|c|c|c|c|}
\hline $\begin{array}{l}N_{\mathrm{T}} \text { in Years } \\
\quad \text { (Period) }\end{array}$ & $\begin{array}{l}\text { D1-81 m } \\
\text { D3-50 m }\end{array}$ & $\begin{array}{l}\text { D1-66 m } \\
\text { D3-50 m }\end{array}$ & $\begin{array}{l}\text { D1-42 m } \\
\text { D3-50 m }\end{array}$ & $\begin{array}{l}\text { D2-81 m } \\
\text { D3-50 m }\end{array}$ & $\begin{array}{l}\text { D2-66 m } \\
\text { D3-50 m }\end{array}$ & $\begin{array}{l}\text { D2-42 m } \\
\text { D3-50 m }\end{array}$ & $\begin{array}{l}\text { Average Reduction } \\
\text { Relative to } N_{\mathrm{T}}=2\end{array}$ \\
\hline $2(2013-2014)$ & 2.243 & 2.235 & 2.202 & 2.179 & 2.174 & 2.144 & - \\
\hline $3(2012-2014)$ & 1.840 & 1.835 & 1.809 & 1.784 & 1.782 & 1.758 & $18 \%$ \\
\hline $4(2011-2014)$ & 1.599 & 1.594 & 1.575 & 1.552 & 1.551 & 1.531 & $29 \%$ \\
\hline 5 (2010-2014) & 1.451 & 1.448 & 1.433 & 1.409 & 1.411 & 1.392 & $35 \%$ \\
\hline $6(2009-2014)$ & 1.336 & 1.333 & 1.320 & 1.301 & 1.302 & 1.283 & $40 \%$ \\
\hline
\end{tabular}

The long-term wind resource uncertainty is included in the $O U$ as a single type of uncertainty among all of those presented in Table 4. When aggregated in Equation (5), all these uncertainty types result in the $\mathrm{OU}$. The calculation of $\mathrm{OU}$ is associated to the resulting long-term time series synthesized by the MCP Vertical Slice method and took into consideration sub datasets from D1 or D2 (both only at $42 \mathrm{~m}$, since these sub datasets were the ones inputted in the MCP analysis) as well as D3. In that sense, the different values of this historical characterization uncertainty were subject to different wind monitoring campaigns durations and, in combination with the fixed values considered for the other uncertainty types, resulted in different values for $O U$, as verified in Table 6. 
Table 6. Overall uncertainty of combinations of data from D1 or D2 (both at $42 \mathrm{~m}$ ) and D3, considering different lengths.

\begin{tabular}{ccccc}
\hline \multirow{2}{*}{$\begin{array}{c}\text { Duration of the Wind Monitoring } \\
\text { Campaign }\end{array}$} & \multicolumn{2}{c}{ D1 at $\mathbf{4 2} \mathbf{~ m}+\mathbf{D 3}$ at $\mathbf{5 0 ~} \mathbf{m}$} & \multicolumn{2}{c}{ D2 at $\mathbf{4 2} \mathbf{~ m}+\mathbf{D 3}$ at $\mathbf{5 0 ~ m}$} \\
\cline { 2 - 5 } & $\begin{array}{c}\text { Historical } \\
\text { Uncertainty [\%] }\end{array}$ & $\begin{array}{c}\text { Overall } \\
\text { Uncertainty [\%] }\end{array}$ & $\begin{array}{c}\text { Historical } \\
\text { Uncertainty [\%] }\end{array}$ & $\begin{array}{c}\text { Overall } \\
\text { Uncertainty [\%] }\end{array}$ \\
\hline 2 years (2013-2014) & 2.202 & 10.670 & 2.144 & 10.658 \\
3 years (2012-2014) & 1.809 & 10.596 & 1.758 & 10.587 \\
4 years (2011-2014) & 1.575 & 10.558 & 1.531 & 10.552 \\
5 years (2010-2014) & 1.433 & 10.538 & 1.392 & 10.533 \\
6 years (2009-2014) & 1.320 & 10.523 & 1.283 & 10.519 \\
\hline
\end{tabular}

The MCP-synthesized time series were then used to estimate the wind power production considering a hypothetic wind farm of 15 wind turbines. The estimation was made by a tool from the Windographer software that automatically executes Equation (6). Arbitrarily, a $2 \mathrm{MW}$ rated power wind turbine with a hub at $80 \mathrm{~m}$ above ground level was elected (Alstom ECO 80/2000 Class II), which is approximately the same height of the MCP extrapolated resulting synthetic data. Its power curve according to air density is seen in Figure 5 [65]. Hence, a wind farm with 15 of these turbines would account for an installed capacity of 30 MW. The results are shown in Table 7 and Figure 6.

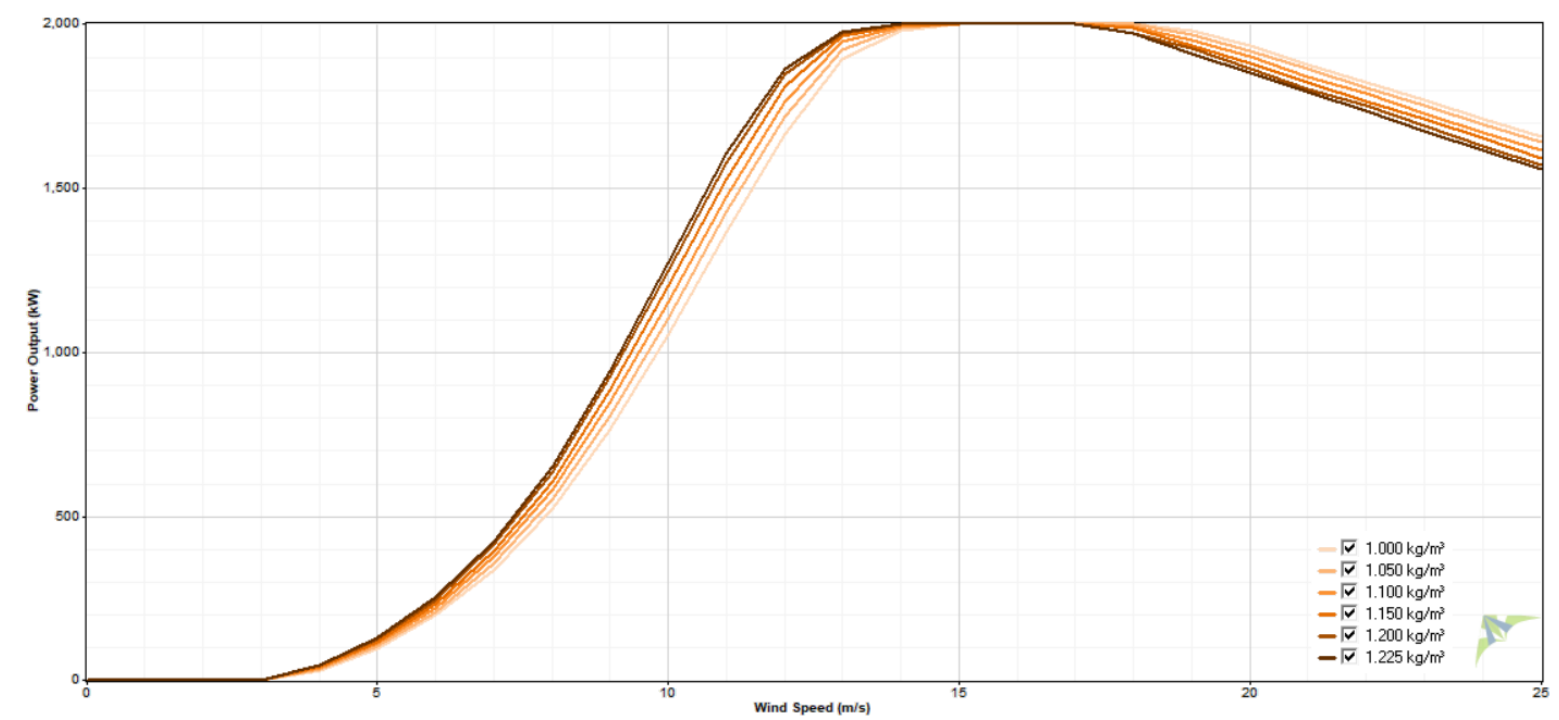

Figure 5. Alstom ECO 80/2000 Class II power output in kW varying to wind speed and air density.

Table 7. E, in GWh/year, for each resulting MCP-synthesized time series, considering the vertically extrapolated data from 42 to $81 \mathrm{~m}$ and varying the length of each time series.

\begin{tabular}{cccccccccccc}
\hline \multirow{2}{*}{ Wind Farm Rated Power } & \multicolumn{4}{c}{ Data from D1 and D3 } & \multicolumn{4}{c}{ Data from D2 and D3 } \\
\cline { 2 - 12 } & 2 Years & 3 Years & 4 Years & 5 Years & 6 Years & 2 Years & 3 Years & 4 Years & 5 Years & 6 Years \\
\hline $30 \mathrm{MW}$ & 95.97 & 95.14 & 95.20 & 93.40 & 93.28 & 126.66 & 124.28 & 122.60 & 121.46 & 120.95 \\
\hline
\end{tabular}

The values in Table 7 and Figure 6 allow concluding that the increase in the duration of the wind monitoring campaign caused the reduction in the estimated quantity of energy to be generated by the hypothetical wind farm in all the cases analyzed. Consequently, the capacity factors would also decrease. These results reflect that longer periods of wind data collection can be more representative of the yearly variability each wind regime is susceptible to.

Conversely, the reduction of the historical uncertainty—and thus the overall uncertainty-acts in the opposite direction, since its isolated effects reflect on the increase of the estimated quantity of energy produced. Yet, these effects are overshadowed by those using larger datasets, which can ultimately provide an energy estimation less prone to errors and, thus, more reliable. 


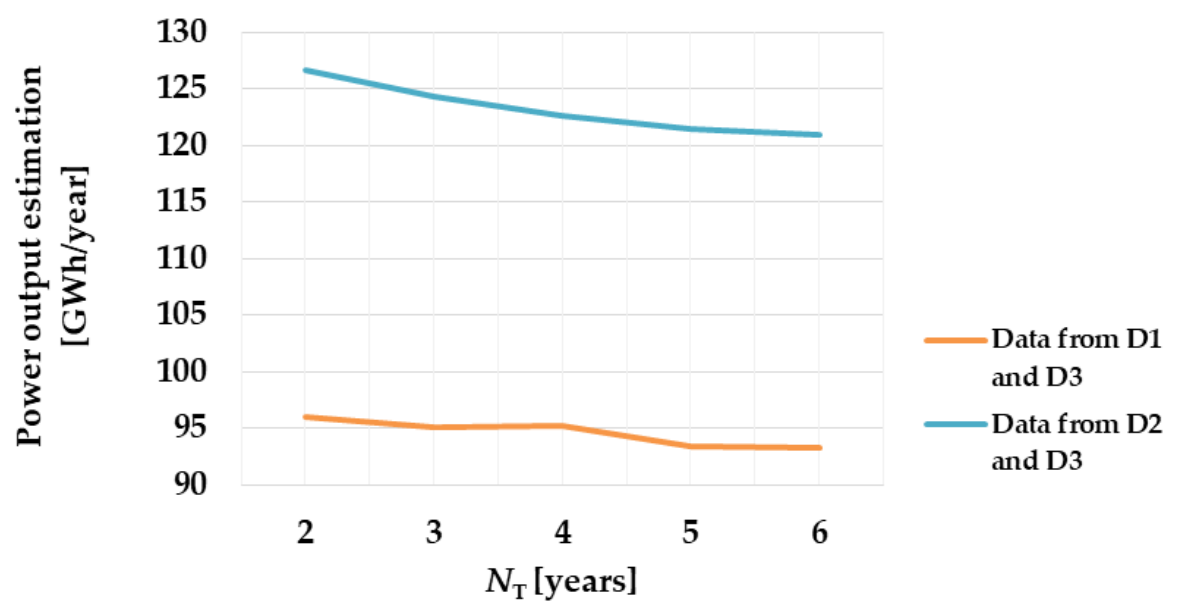

Figure 6. Wind farm power output estimation according to different $N_{\mathrm{T}}$.

\section{Conclusions}

This study reveals that a wind monitoring campaign contemplating a more extended duration may allow for better interpretation of the variability in the availability of wind resources in a given target location under the application of the MCP technique. Hence, it is possible to reduce the uncertainty related to the historical characterization of the wind regime in that location, contributing to reducing the overall uncertainty of a WRA. Under the conditions of the recent increase from 24 to 36 months in the minimum length of required wind data recording for a wind farm project to participate in an energy auction in Brazil, the uncertainty related to the historical characterization of wind resources for the data used in this research could be reduced by approximately $18 \%$.

This reduction in the uncertainties group contributes to an increase in the power output estimation of a wind farm, due to the lower overall uncertainty value. This sole fact could lead to an overestimation, which, in turn, may affect the financial structure of a wind farm project. Nevertheless, from the data considered for this research, it was shown that bigger datasets implied a reduction in the estimated energy generation by a wind farm, even considering the overall uncertainty reduction.

The acknowledgement of the outcomes that should follow this expansion in the minimum length of the wind measurement campaign, is perceived as an important contribution to the state of the art pervading the WRA. It seems that the recent new Brazilian regulation could help to enhance a WRA, resulting in more accurate, less prone to overestimation, wind power output estimations. It is understandable that, even if an underestimated energy production is generated by the end of the WRA, the electric sector as a whole may benefit when considering its reliability and expected guaranteed power to be delivered to the grid. For that reason, the findings within this paper should support wind power industry stakeholders to grasp the modifications in the Brazilian wind power sector guidelines, hoping it could also influence decision-making among different countries and their power sectors' regulatory frameworks. Lastly, it is worth mentioning that incrementing the wind monitoring campaign duration implies more expenses to a project; making it not financially healthy to increase the former indefinitely. The optimum duration-considering costs and accurate power generation outputs-is an interesting topic for further discussion.

Author Contributions: Conceptualization, J.V.P.M. and E.A.F.; methodology, J.V.P.M.; software, J.V.P.M.; formal analysis, J.V.P.M.; resources, J.V.P.M.; writing—original draft preparation, J.V.P.M.; writing—review and editing, E.A.F. and I.L.S.; supervision, E.A.F. and I.L.S.; project administration, E.A.F. and I.L.S.

Funding: The authors state that this study was partly financed by a Research \& Development project between the Brazilian National Electrical Energy Agency (ANEEL-Agência Nacional de Energia Elétrica) and the University of São Paulo (USP). The project's code and name are PD-00061-0054/2016 “Efficiency Analysis of the Energy Complimentary Storage Paired with Hydropower Plants with Electrochemical and Hydrogen Storage Technologies". Also, one of the researchers was financed by the Coordenação de Aperfeiçoamento de Pessoal de Nível Superior-Brasil (CAPES)—Finance Code 001. 
Acknowledgments: The authors are grateful to the Brazilian private company that provided data from the two meteorological masts that recorded the information contained in D1 and D2. The authors acknowledge, as well, the Global Modeling and Assimilation Office (GMAO) at NASA Goddard Space Flight Center, which have provided the MERRA data (D3 and D5) used in this research through the NASA GES DISC online archive. Finally, the R\&D project between ANEEL and USP, which has provided with funding for this and other researches within the realm of power generation with renewable energy and associated storage, as well as data for solar, wind and hydric resources recorded at Porto Primavera.

Conflicts of Interest: The authors declare no conflict of interest.

\section{Appendix A}

Access to an extra database for a second target location (situated close to the hydropower plant of Porto Primavera, in the state of São Paulo, Brazil) was granted to try and pursue for the generalization of this research's results. The database consisted of anemometric wind speed and direction recordings for a period of 24 months at a height of $10 \mathrm{~m}$ above ground level. The information in it, however, was insufficient to perform certain steps within the WRA, such as vertical extrapolation and the MCP analysis. The former would require measurements of wind speed at different heights so the vertical profile could be outlined properly and, as for the latter, long-term reference data (given by MERRA reanalysis) of a location $50 \mathrm{~km}$ close to that target location presented a squared Pearson correlation index of 0.17 between reference and location wind speed data, which is considered too low for the MCP analysis to be reliable [25]. Moreover, since the emphasis of this research was to explore the influence of the wind monitoring campaign with a duration of two or more whole years, this database was completely disregarded since it comprised only 24 months of measurement. The information of both target and reference databases is presented in Table A1.

Table A1. Characterization of the databases of a second target location and the MERRA reanalysis used as the reference location data.

\begin{tabular}{cccccccc}
\hline Data Base & Location & $\begin{array}{c}\text { Altitude } \\
{[\mathbf{m}]}\end{array}$ & $\begin{array}{c}\text { Measurement } \\
\text { Height }[\mathbf{m}]\end{array}$ & $\begin{array}{c}\text { Initial } \\
\text { Measurement } \\
\text { Date }\end{array}$ & $\begin{array}{c}\text { Final } \\
\text { Measurement } \\
\text { Date }\end{array}$ & $\begin{array}{c}\text { Periodicity } \\
{[\text { Minutes] }}\end{array}$ & $\begin{array}{c}\text { Average Wind } \\
\text { Speed [m/s] }\end{array}$ \\
\hline 4 & Target & 258 & 10 & 20 January 2017 & 19 January 2019 & 60 & 3.94 \\
5 & Reference & 247 & 50 & 01 January 1980 & 01 August 2019 & 60 & 4.15 \\
\hline
\end{tabular}

\section{References}

1. Empresa de Pesquisa Energética (Brazil). Ten-Year Energy Expansion Plan 2026; Ministério de Minas e Energia/Empresa de Pesquisa Energética: Brasilia, Brazil, 2017. Available online: http://www.epe.gov.br/ sites-pt/publicacoes-dados-abertos/publicacoes/PublicacoesArquivos/publicacao-40/PDE2026.pdf (accessed on 6 April 2018).

2. Empresa de Pesquisa Energética (Brazil). Brazilian Energy Balance 2017-Year 2016; Empresa de Pesquisa Energética: Rio de Janeiro, Brazil, 2017. Available online: https://ben.epe.gov.br/downloads/Relatorio_Final_ BEN_2017.pdf (accessed on 6 April 2018).

3. Azuela Elizondo, G.; Barroso, L.; Khanna, A.; Wang, X.; Wu, Y.; Cunha, G. Performance of Renewable Energy Auctions: Experience in Brazil, China and India. World Bank Group-Energy and Extractives Global Practice Group; The World Bank: Washington, DC, USA, 2014; pp. 1-39.

4. Cunha, G.; Barroso, A.L.; Bezerra, B. Lessons learned from the auction-based approach to integrate wind generation in the Brazilian electricity market. In Proceedings of the CIGRE Session 2014, Paris, France, 26-29 August 2014; Available online: https://www.psr-inc.com/wp-content/uploads/articles/Bienal_2014_ C5_Luiz_Barroso.pdf (accessed on 17 September 2019).

5. Chade Ricosti, J.F.; Sauer, I.L. An assessment of wind power prospects in the Brazilian hydrothermal system. Renew. Sustain. Energy Rev. 2013, 19, 742-753. [CrossRef]

6. Jain, P. Wind Energy Engineering, 1st ed.; The McGraw-Hill Companies, Inc.: New York, NY, USA, 2011.

7. Brower, M.C. Wind Resource Assessment: A Practical Guide to Developing a Wind Project, 1st ed.; John Wiley \& Sons, Inc.: Hoboken, NJ, USA, 2012. 
8. Zobaa, A.F.; Bansal, R.C. Handbook of Renewable Energy Technology, 1st ed.; World Scientific Publishing Co. Pte. Ltd.: Singapore, 2011; pp. 69-95.

9. Watson, S. Quantifying the variability of wind energy. Wiley Interdiscip. Rev. Energy Environ. 2014, 3, 330-342. [CrossRef]

10. Bodini, N.; Lundquist, J.K.; Zardi, D.; Handschy, M. Year-to-year correlation, record length, and overconfidence in wind resource assessment. Wind Energy Sci. 2016, 1, 115-128. [CrossRef]

11. Pryor, S.C.; Barthelmie, R.J.; Schoof, J.T. Inter-annual variability of wind indices across Europe. Wind Energy 2006, 9, 27-38. [CrossRef]

12. Haupt, S.E.; Copeland, J.; Cheng, W.Y.Y.; Zhang, Y.; Ammann, C.; Sullivan, P. A method to assess the wind and solar resource and to quantify interannual variability over the United States under current and projected future climate. J. Appl. Meteorol. Climatol. 2016, 55, 345-363. [CrossRef]

13. Jiang, B.; Zhang, S.; Wu, H.; Ding, J.; Hou, P. Uncertainty of the Offshore Wind Energy Resource Assessment due to Long-term. In Proceedings of the 2nd International Conference on Sustainable Development (ICSD 2016), Xi'an, China, 2-4 December 2017; Volume 94, pp. 298-303.

14. Krakauer, N.; Cohan, D. Interannual Variability and Seasonal Predictability of Wind and Solar Resources. Resources 2017, 6, 29. [CrossRef]

15. Engeland, K.; Borga, M.; Creutin, J.D.; François, B.; Ramos, M.H.; Vidal, J.P. Space-time variability of climate variables and intermittent renewable electricity production-A review. Renew. Sustain. Energy Rev. 2017, 79, 600-617. [CrossRef]

16. Rogers, A.L.; Rogers, J.W.; Manwell, J.F. Uncertainties in Results of Measure-Correlate-Predict Analyses. Am. Wind Energy Assoc. 2005. Available online: https://www.researchgate.net/profile/James_ Manwell/publication/237439775_Uncertainties_in_Results_of_Measure-Correlate-Predict_Analyses/links/ 004635307bcf620bd6000000.pdf (accessed on 17 September 2019).

17. Rose, S.; Apt, J. What can reanalysis data tell us about wind power? Renew. Energy 2015, 83, 963-969. [CrossRef]

18. Rose, S.; Apt, J. Quantifying sources of uncertainty in reanalysis derived wind speed. Renew. Energy 2016, 94, 157-165. [CrossRef]

19. Lackner, M.A.; Rogers, A.L.; Manwell, J.F. Uncertainty Analysis in MCP-Based Wind Resource Assessment and Energy Production Estimation. J. Sol. Energy Eng. 2008, 130, 031006. [CrossRef]

20. Gass, V.; Strauss, F.; Schmidt, J.; Schmid, E. Assessing the effect of wind power uncertainty on profitability. Renew. Sustain. Energy Rev. 2011, 15, 2677-2683. [CrossRef]

21. Drew, D.R.; Barlow, J.F.; Cockerill, T.T.; Vahdati, M.M. The importance of accurate wind resource assessment for evaluating the economic viability of small wind turbines. Renew. Energy 2015, 77, 493-500. [CrossRef]

22. Empresa de Pesquisa Energética (Brazil). Expansão da Geração: Empreendimentos Eólicos-Instruções para Solicitação de Cadastramento e Habilitação Técnica com Vistas à Participação nos Leilões de Energia Elétrica. Available online: http://epe.gov.br/sites-pt/leiloes-de-energia/Documents/Instrucoes/EPE-DEE-017_2009_ R14_2017_EOL.pdf (accessed on 6 September 2019).

23. Taylor, M.; Mackiewicz, P.; Brower, M.C.; Markus, M. An analysis of wind resource uncertainty in energy production estimates. In Proceedings of the European Wind Energy Conference and Exhibition, London, UK, 22-25 November 2004.

24. Rienecker, M.M.; Suarez, M.J.; Gelaro, R.; Todling, R.; Bacmeister, J.; Liu, E.; Bosilovich, M.G.; Schubert, S.D.; Takacs, L.; Kim, G.K.; et al. MERRA: NASA's modern-era retrospective analysis for research and applications. J. Clim. 2011, 24, 3624-3648. [CrossRef]

25. Carta, J.A.; Velázquez, S.; Cabrera, P. A review of measure-correlate-predict (MCP) methods used to estimate long-term wind characteristics at a target site. Renew. Sustain. Energy Rev. 2013, 27, 362-400. [CrossRef]

26. Brower, M.C. The use of NCEP/NCAR reanalysis data in MCP. In Proceedings of the European Wind Energy Conference and Exhibition, Athens, Greece, 27 February-2 March 2006.

27. Liléo, S.; Petrik, O. Investigation on the use of NCEP/NCAR, MERRA and NCEP/CFSR reanalysis data in wind resource analysis. In Proceedings of the European Wind Energy Conference \& Exhibition, Brussels, Belgium, 14-17 March 2011; Volume 10.

28. Ayotte, K.W.; Davy, R.J.; Coppin, P.A. A simple temporal and spatial analysis of flow in complex terrain in the context of wind energy modelling. Bound. Layer Meteorol. 2001, 98, 275-295. [CrossRef]

29. Landberg, L.; Myllerup, L.; Rathmann, O.; Petersen, E.L.; Jørgensen, B.H.; Badger, J.; Mortensen, N.G. Wind resource estimation-An overview. Wind Energy 2003, 6, 261-271. [CrossRef] 
30. Prasad, R.D.; Bansal, R.C.; Sauturaga, M. Some of the design and methodology considerations in wind resource assessment. IET Renew. Power Gener. 2009, 3, 53-64. [CrossRef]

31. Deane, J.P.; Moehrlen, C.S.; Mckeogh, E.J. Wind data analysis. In Proceedings of the European Wind Energy Conference, Munich, Germany, 22-26 October 2001; pp. 846-849.

32. Nielsen, M.; Landberg, L.; Mortensen, N.G.; Barthelmie, R.J.; Joensen, A. Application of the measure-correlate-predict for wind resource assessment. In Proceedings of the 2001 European Wind Energy Conference, Copenhagen, Denmark, 2-6 July 2001; pp. 773-776.

33. Riedel, V.; Strack, M.; Waldl, H. Robust approximation of functional relationships between meteorological data: Alternative measure-correlate-predict algorithms. In Proceedings of the European Wind Energy Conference, Munich, Germany, 22-26 October 2001; pp. 806-809.

34. Anderson, M. A Review of MCP Techniques. A Review of MCP Techniques; Renewable Energy Systems Ltd.: Kingsland, UK, 2004.

35. King, C.; Hurley, B. The SpeedSort, DynaSort and Scatter wind correlation methods. Wind Eng. 2009, 29, $217-242$. [CrossRef]

36. Leblanc, M.; Schoborg, D.; Cox, S.; Haché, A.; Tindal, A. Is a Non-linear MCP method a useful tool for North American wind regimes? In Proceedings of the AWEA 2009 Windpower Conference and Exhibition, Chicago, IL, USA, 30 April-8 May 2009.

37. Beltran, J.; Cosculluela, L.; Pueyo, C.; Melero, J.J. Comparison of measure-correlate-predict methods in wind resource assessments. In Proceedings of the European Wind Energy Conference and Exhibition, Warsaw, Poland, 20-23 April 2010; Volume 5, pp. 3280-3286.

38. Derrick, A. Development of the measure-correlate-predict strategy for site assessment. In Proceedings of the Fourteenth British Wind Energy Conference, Nottingham, England, 25-27 March 1992; pp. 259-265.

39. Thøgersen, M.L.; Motta, M.; Sørensen, T.; Nielsen, P. Measure-correlate-predict methods: Case studies and software implementation. In Proceedings of the European Wind Energy Conference \& Exhibition, Berlin, Germany, 4-6 December 2007.

40. Lieshout, P. Improvements in AEP calculations using IEC 61400. Wind. Int. 2010, 6. Available online: https://www.windtech-international.com/editorial-features/improvements-in-aepcalculations-using-iec-61400 (accessed on 17 September 2019).

41. Mortimer, A.A. A new correlation/prediction method for potential wind farm sites. In Proceedings of the 16th British Wind Energy Conference, Sterling, England, 15-17 June 1994; pp. 349-352.

42. Salmon, J.R.; Walmsley, J.L. A two-site correlation model for wind speed, direction and energy estimates. J. Wind Eng. Ind. Aerodyn. 1999, 79, 233-268. [CrossRef]

43. García-Rojo, R. Algorithm for the Estimation of the Long-Term Wind Climate at a Meteorological Mast Using a Joint Probabilistic Approach. Wind Eng. 2004, 28, 213-223. [CrossRef]

44. Clive, P.J.M. Non-linearity in MCP with Weibull. Wind Eng. 2008, 32, 319-324. [CrossRef]

45. Carta, J.A.; Velázquez, S. A new probabilistic method to estimate the long-term wind speed characteristics at a potential wind energy conversion site. Energy 2011, 36, 2671-2685. [CrossRef]

46. Lambert, T.; Grue, A. The Matrix Time Series Method for MCP. In Proceedings of the AWEA Windpower Conference and Exhibition, Atlanta, GA, USA, 3-6 June 2012.

47. Weekes, S.M.; Tomlin, A.S. Comparison between the bivariate Weibull probability approach and linear regression for assessment of the long-term wind energy resource using MCP. Renew. Energy 2014, 68, 529-539. [CrossRef]

48. Addison, J.F.D.; Hunter, A.; Bass, J.; Rebbeck, M. A neural network version of the measure correlate predict algorithm for estimating wind energy yield. In Proceedings of the 13th International Congress on Condition Monitoring and Diagnostic Engineering Management, Houston, TX, USA, 3-8 December 2000; pp. 917-922.

49. Probst, O.; Cárdenas, D. State of the art and trends in wind resource assessment. Energies 2010, 3, 1087-1114. [CrossRef]

50. Walls, L.; Kline, J.; Kline, Z.; City, O. Long-term Wind Speed Estimates from Short-term Data: So Many Ways to Get It Wrong. In Proceedings of the AWEA wind Resource Assessment Workshop, Oklahoma City, OK, USA, 14 September 2010.

51. Carta, J.A.; Velázquez, S.; Matías, J.M. Use of Bayesian networks classifiers for long-term mean wind turbine energy output estimation at a potential wind energy conversion site. Energy Convers. Manag. 2011, 52, 1137-1149. [CrossRef] 
52. Zhang, J.; Chowdhury, S.; Messac, A.; Hodge, B.M. A hybrid measure-correlate-predict method for long-term wind condition assessment. Energy Convers. Manag. 2014, 87, 697-710. [CrossRef]

53. Mifsud, M.D.; Sant, T.; Farrugia, R.N. A comparison of Measure-Correlate-Predict Methodologies using LiDAR as a candidate site measurement device for the Mediterranean Island of Malta. Renew. Energy 2018, 127, 947-959. [CrossRef]

54. Liu, X.; Lai, X.; Zou, J. A New MCP Method of Wind Speed Temporal Interpolation and Extrapolation Considering Wind Speed Mixed Uncertainty. Energies 2017, 10, 1231. [CrossRef]

55. Carta, J.A.; Cabrera, P.; Matías, J.M.; Castellano, F. Comparison of feature selection methods using ANNs in MCP-wind speed methods. A case study. Appl. Energy 2015, 158, 490-507. [CrossRef]

56. Díaz, S.; Carta, J.A.; Matías, J.M. Comparison of several measure-correlate-predict models using support vector regression techniques to estimate wind power densities. A case study. Energy Convers. Manag. 2017, 140, 334-354. [CrossRef]

57. Díaz, S.; Carta, J.A.; Matías, J.M. Performance assessment of five MCP models proposed for the estimation of long-term wind turbine power outputs at a target site using three machine learning techniques Support vectors in Support Vector Machine Support Vector Machine for regression. Appl. Energy 2018, 209, 455-477. [CrossRef]

58. Weekes, S.M.; Tomlin, A.S. Data efficient measure-correlate-predict approaches to wind resource assessment for small-scale wind energy. Renew. Energy 2014, 63, 162-171. [CrossRef]

59. Rogers, A.L.; Rogers, J.W.; Manwell, J.F. Comparison of the performance of four measure-correlate-predict algorithms. J. Wind Eng. Ind. Aerodyn. 2005, 93, 243-264. [CrossRef]

60. Dinler, A. A new low-correlation MCP (measure-correlate-predict) method for wind energy forecasting. Energy 2013, 63, 152-160. [CrossRef]

61. Velázquez, S.; Carta, J.A.; Matías, J.M. Comparison between ANNs and linear MCP algorithms in the long-term estimation of the cost per $\mathrm{kW}$ h produced by a wind turbine at a candidate site: A case study in the Canary Islands. Appl. Energy 2011, 88, 3869-3881. [CrossRef]

62. Lackner, M.A.; Rogers, A.L.; Manwell, J.F.; McGowan, J.G. A new method for improved hub height mean wind speed estimates using short-term hub height data. Renew. Energy 2010, 35, 2340-2347. [CrossRef]

63. DEWI German Wind Energy Institute. Wind Resource Assessment Techniques; Course: Wilhelmshaven, Germany, 2000.

64. BBB Umwelttechnik GmbH. Realização de Projetos em Energia Eólica; University of São Paulo: Sao Paulo, Brazil, 2015.

65. Windographer Professional Edition, version 4.1.12; Copyright ${ }^{\circledR} 2018$ AWS Truepower; A UL Company: Saint Aubin, France, 2018.

66. Lee, S.; Churchfield, M.J.; Moriarty, P.J.; Jonkman, J.; Michalakes, J. A numerical study of atmospheric and wake turbulence impacts on wind turbine fatigue loadings. J. Sol. Energy Eng. Trans. ASME 2013, 135, 37-41. [CrossRef]

67. Nandi, T.N.; Herrig, A.; Brasseur, J.G. Non-steady wind turbine response to daytime atmospheric turbulence. Philos. Trans. R. Soc. A 2017, 375, 20160103. [CrossRef]

(C) 2019 by the authors. Licensee MDPI, Basel, Switzerland. This article is an open access article distributed under the terms and conditions of the Creative Commons Attribution (CC BY) license (http://creativecommons.org/licenses/by/4.0/). 